\title{
Doses de NPK em tomateiro cv. Marmande e seu desempenho a campo no Cerrado
}

\author{
Valéria Lima da Silva1, Alessandra Conceição de Oliveira ${ }^{2}$, Geyci Aires Farias², \\ Weslian Vilanova da Silva², Lucely Pereira da Silva ${ }^{2}$ \\ ${ }^{1}$ Universidade Estadual de Goiás, Campus de São Luís de Montes Belos, Goiás, Brasil. E-mail:valeria.silva21@hotmail.com. \\ ${ }^{2}$ Universidade do Estado de Mato Grosso, Câmpus Nova Xavantina, Mato Grosso, Brasil. E-mail: acoliviera@ hotmail.com, \\ geyci_farias@hotmail.com,wly_7@hotmail.com, lulysortuna@hotmail.com
}

Recebido: 08/09/2017; Aceito: 02/02/2018.

\section{RESUMO}

Atender as necessidades nutricionais das mudas é fundamental para o desempenho da planta no campo. Nesse sentido, objetivou-se com esse trabalho avaliar o efeito de doses de NPK na fertirrigação de mudas de tomate e seu desempenho a campo. O delineamento experimental utilizado foi em blocos ao acaso com cinco tratamentos e quatro repetições. Os tratamentos foram doses de NPK $\left(0 ; 1,5 ; 3,0 ; 4,5\right.$ e $\left.6,0 \mathrm{mg} \mathrm{dm}^{-3}\right)$ na fertirrigação das mudas. Estas, quando foram a campo, tiveram maior desempenho, acima de 4,5 $\mathrm{mg} \mathrm{dm}^{-3}$. Conclui-se que a cv. Marmande obteve o melhor desenvolvimento e as mudas quando foram a campo tiveram maior desempenho com doses a partir de 4,5 $\mathrm{mg} \mathrm{dm}^{-3}$, mostrando que o tomateiro responde a adubação NPK de forma positiva.

Palavras-chave: Solanum lycopersicum L., adubação, crescimento.

\section{Rates of NPK in tomato cv. Marmande and its performance to the field in the Cerrado}

\begin{abstract}
Meeting the nutritional needs of seedlings is critical to the performance of the plant in the field. In this sense, the objective of this work was to evaluate the effect of NPK rates on the fertirrigation of tomato seedlings and their performance in the field. The experimental design was a randomized block design with five treatments and four replications. The treatments were NPK rates $\left(0,1.5,3.0,4.5\right.$ and $\left.6.0 \mathrm{mg} \mathrm{dm}^{-3}\right)$ in the fertirrigation of the seedlings. These, when they went to the field, had higher performance, above $4.5 \mathrm{mg} \mathrm{dm}^{-3}$. It is concluded that cv. Marmande obtained the best development and the seedlings when they were in the field had higher performance with doses from $4.5 \mathrm{mg} \mathrm{dm}^{-3}$, showing that the tomato responds to NPK fertilization in a positive way.
\end{abstract}

Key words: Solanum lycopersicum L. fertilization, growth. 


\section{Introdução}

O tomateiro (Solanum lycopersicum L.) é uma das hortaliças mais consumidas no mundo. No Brasil, o segmento de tomate de mesa contribuiu com $76 \%$ da produção e os $24 \%$ restantes destinaram-se ao processamento industrial (IBGE, 2014). Goiás se destaca no cenário nacional, sendo responsável pela maior produção de tomate com uma produtividade de $88.047 \mathrm{~kg} / \mathrm{ha}^{-1}$ (IBGE, 2014).

A cultura do tomate se adapta melhor ao cultivo em clima tropical de altitude, como o das regiões de planalto ou serranas, mas se desenvolve também em regiões de clima tropical ou temperado, seco e com luminosidade alta (FILGUEIRA, 2005). A produção de mudas em bandejas é uma técnica bastante vantajosa e propicia redução do ciclo da planta no campo, minimiza o custo com mão de obra, principalmente com tratos culturais iniciais e melhora o aproveitamento das sementes, além de aumentar a uniformidade das mudas (MINAMI, 1995).

O sistema de produção de mudas em bandejas possibilita diversas vantagens, como redução de custos com espaço físico e melhor controle de pragas (MINAMI, 1995). Produzir as mudas em ambiente em viveiros é umas das melhores alternativas para o crescimento saudável das plantas, principalmente por se manter o nível de temperatura média adequado. A facilidade de se controlar a irrigação evitando o excesso de água também é um ponto positivo do cultivo em viveiros; em campo aberto, por exemplo, as chuvas poderiam favorecer a ocorrência de doenças e comprometer o pleno desenvolvimento da planta (BEZERRA 2003).

A produção de mudas constitui uma das etapas mais importantes do sistema produtivo hortícola, sendo altamente dependente da utilização de insumos (SILVEIRA et al., 2002). Neste sentido, a adubação complementar pode causar impactos positivos, visto que a cultura do tomate tem requerimentos nutricionais específicos que podem ser supridos pela adição de fertilizantes químicos ou de orgânicos (FERREIRA et al., 2010).

A adubação NPK influencia os processos envolvidos no crescimento e desenvolvimento das plantas, alterando as distribuições de assimilados entre as partes vegetativas e reprodutivas. $\mathrm{O} \mathrm{N}$ é essencial durante o ciclo da planta, pois aumenta a massa fresca das folhas, frutos e massa seca das raízes. A deficiência de $\mathrm{N}$ durante o período de frutificação reduz a produção e altera a coloração dos frutos (GENUNCIO, 2009). O P é exigido em pequenas quantidades durante a fase de florescimento e frutificação, sua deficiência inicia-se com um menor desenvolvimento das plantas, seguido de clorose nas folhas (FARIA et al., 1999). Segundo Alvarenga (2004) a adubação potássica pode aumentar em $30 \%$ a produtividade do tomateiro, pois impede a queda e melhora a qualidade comercial dos frutos. A deficiência de $\mathrm{K}$ causa crescimento lento, alteração no processo fotossintético e os frutos com menor firmeza e teor baixo de sólidos solúveis (FELTRIN et al, 2005).

Diante disso, objetivou-se com esse trabalho avaliar o efeito de doses de NPK na fertirrigação de mudas de tomate e seu desempenho a campo.

\section{Material e Métodos}

O trabalho foi desenvolvido no campo experimental da Universidade do Estado de Mato Grosso (UNEMAT), Campus de Nova Xavantina - MT, em uma área situada nas coordenadas geográficas de latitude $14^{\circ} 41^{\prime} 25^{\prime \prime}$ sul e longitude $52^{\circ} 20^{\prime} 55^{\prime \prime}$ a oeste de Greenwich, e altitude de 275 metros dentro do parque municipal Mário Viana (NIMER,1989).

O clima na região, de acordo com a classificação de Koppen é AW (SAMPAIO et al.; 2011), apresentando duas estações bem definidas, uma seca de maio a setembro e uma chuvosa de outubro a abril (BIUDES et al.,2011).

O experimento foi conduzido no período de 23 de Março de 2016 a 18 de Maio de 2016. As mudas foram produzidas em viveiro telado com $9 \mathrm{~m}$ de largura X 9m de comprimento e 2,5 de altura e malha para $50 \%$ de sombreamento. Foi utilizada a cultivar Marmande com semeadura feita em bandejas de polietileno com 200 células no dia 26 de março de 2016. Foram semeadas três sementes por célula preenchidas com o substrato comercial Carolina. O desbaste ocorreu após a germinação de mais de $90 \%$ das sementes deixando apenas a planta mais vigorosa.

Foram avaliadas cinco doses do formulado NPK (10:10:10) na fertirrigação das mudas; cada bandeja com 5 tratamentos sendo $\mathrm{T} 1=0 ; \mathrm{T} 2=1,5 ; \mathrm{T} 3=3,0 ; \mathrm{T} 4=$ $4 ; 5$ e T5=6,0 $\mathrm{mg} \mathrm{dm}^{-}{ }^{3}$ Cada tratamento com 20 plantas, sendo avaliadas apenas as 6 plantas centrais de cada tratamento e as demais consideradas como bordadura. $\mathrm{O}$ delineamento foi em blocos casualizados, com quatro repetições. A solução nutritiva foi diluída em água e aplicada com o auxílio de uma seringa de 5,0 mL por célula, em intervalo de 7 dias, aos 15, 25 e 32 dias após semeadura (DAS).

As mudas foram transplantadas com 27 DAS no espaçamento de $1,30 \mathrm{~m}$ entrelinhas e $0,40 \mathrm{~m}$ entre plantas. $\mathrm{O}$ delineamento experimental foi em blocos ao acaso, com quatro repetições sendo transplantadas seis plantas por parcela. A irrigação foi feita com o auxílio de um regador manual, de acordo com a necessidade hídrica das mudas e o controle de plantas espontâneas foram realizadas de forma manual, conforme a necessidade do local. O solo da área foi classificado como Latossolo Vermelho-Amarelo, de textura média, 
cujas características químicas foram: $\mathrm{pH}=6,0 ; \mathrm{Ca}=3,2$ $\mathrm{cmol}_{\mathrm{c}} \mathrm{dm}^{-3} ; \mathrm{Mg}=0,8 \mathrm{cmol}_{\mathrm{c}} \mathrm{dm}^{-3} ; \mathrm{Al}=0,1 \mathrm{cmol}_{\mathrm{c}} \mathrm{dm}^{-}$; $\mathrm{P}($ Mehlich $)=13,9 \mathrm{mg} \mathrm{dm}^{-3} ; \mathrm{K}=0,2 \mathrm{cmol}_{\mathrm{c}} \mathrm{dm}^{-3} ; \mathrm{V}=$ $75 \%$.

A avaliação das mudas ocorreu 38 DAS, analisandose seis plantas por tratamento quanto às seguintes características: altura da parte aérea (APA), comprimento da raiz (CR), número de folhas (NF), diâmetro do caule (DC), massa fresca das folhas (MFF), caule (MFC) e raiz (MFR) e massa seca das folhas (MSF), caule (MSC) e raiz (MSR).

As avaliações das plantas no campo ocorreram durante 21 dias após o transplante (DAT), sendo avaliado a altura de planta, número de folhas e diâmetro do caule três vezes por semana, a fim de verificar a sobrevivência das mudas. As mudas de tomateiro foram irrigadas com um regador manual, duas vezes ao dia, sendo período matutino e vespertino, e o controle de plantas adventícias realizados de forma manual, no qual é fácil o manuseio.

Os resultados dos experimentos foram submetidos a análise de regressão pelo programa computacional SISVAR 4.0 (FERREIRA, 2000).

\section{Resultados e Discussão}

Analisando a Figura 1, observa-se que o número de folhas houve efeito quadrático com máximo valor estimado em 6,7 folhas por plântula para a dose de 3,44 $\mathrm{mg} \mathrm{dm}-{ }^{3}$ de NPK e para altura da parte aérea, a média encontrada no projeto foi de $6,36 \mathrm{~cm}$, sendo este não significativo para as diferentes doses de NPK. Para a relação diâmetro de colo e comprimento de raiz, não foram significativos nas diferentes doses de NPK, ou seja, quando comparadas a testemunha e a maior dose 6,0 $\mathrm{mg} \mathrm{dm}^{3}{ }^{3}$ de NPK, mostrando assim que não há necessidade de adubação, obtendo assim as médias 1,85 $\mathrm{mm}$ e $6,04 \mathrm{~cm}$, respectivamente.

Resultados semelhantes foram encontrados por outros autores trabalhando com adubação na produção de mudas de outras espécies da mesma família botânica, a exemplo da berinjela (MOREIRA et al., 2010) e tomate (SILVEIRA et al., 2002), nas quais o menor número de folhas ocorreu em mudas que não receberam fertirrigação.

As doses de NPK não influenciaram na relação altura e diâmetro do colo, com média de $3,46 \mathrm{~cm} / \mathrm{mm}$, mostrando que não há necessidade de adubação NPK quando se avalia altura de plantas e diâmetro do colo. Batista (2010), estudando o manejo da fertirrigação NPK 904-14-08) na produção de mudas de chicória obteve resultados positivos que proporcionaram maiores valores de área foliar, massa fresca da parte aérea, massa seca da parte aérea, quando comparadas com as plantas que não foram submetidas a fertirrigação.
Na Figura 2, a massa fresca total e seca total nas menores doses de 1,78 e $1,56 \mathrm{mg} \mathrm{dm}-{ }^{3}$ proporcionaram os menos pesos, respectivamente, e $6,0 \mathrm{mg} \mathrm{dm}-{ }^{3}$ foi a que ajustou um maior peso das mesmas, ou seja, as doses maiores de NPK foram eficientes para maior peso de biomassa da cultura tomateiro cv. Marmande.

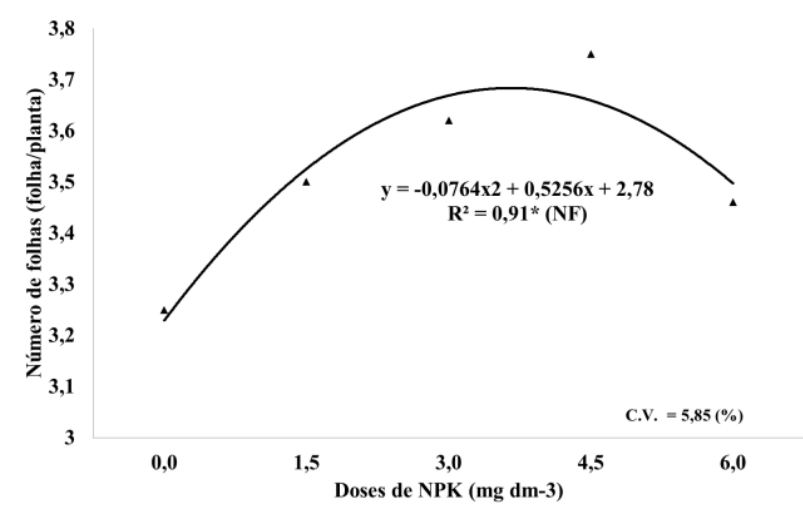

Figura 1. Número de folhas de mudas de tomateiro cv. Marmande, em Nova Xavantina-MT-2016.

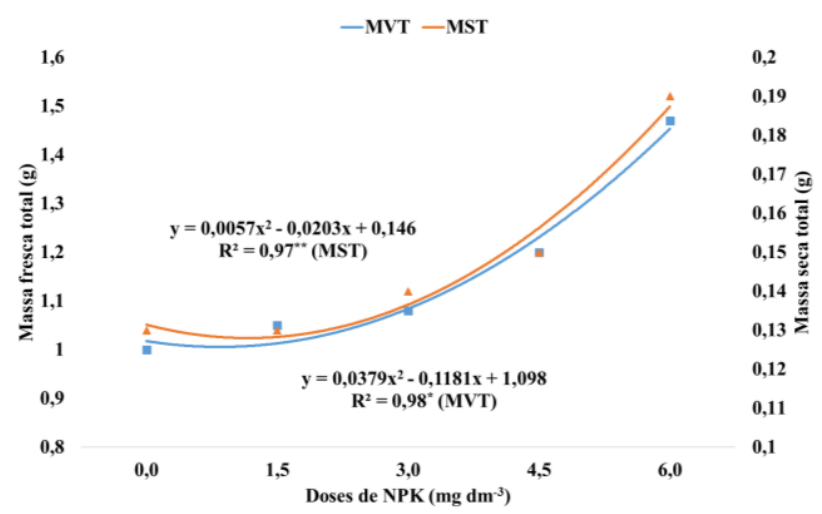

Figura 2. Massa fresca e seca total das mudas de tomateiro cv. Marmande, em Nova Xavantina-MT-2016.

Conforme Taiz e Zieger (1998), a melhor forma de se avaliar o crescimento de uma planta seria a massa seca, pois a massa fresca é um parâmetro muito sensível às oscilações hídricas, uma vez que a maior parte dos vegetais é formada por água; com relação a matéria seca total das mudas observa-se um valor de $0,19 \mathrm{~g}$ na dose de $6,0 \mathrm{mg} \mathrm{dm}^{3}$ de NPK.

Ensinas et al. (2009) testando níveis de fertirrigação nas características morfofisiológicas de mudas de rúcula, avaliou que a maior dose do fertilizante na água de irrigação proporcionou, nas condições deste experimento, os maiores valores de massa fresca da parte área das plantas, sendo que a dose de $\mathrm{Ml} \mathrm{L}^{-1}$ apresentou resultado de $2,3 \mathrm{mg} \mathrm{dm}^{3}$ de MSPA. Na formação de mudas de alface americana (Lactuca sativa L. var Tainá), Biscaro et al. (2003), observaram que os maiores valores de altura e massa seca da parte aérea foram obtidos com plantas irrigadas com água receptora de efluentes urbanos apresentando alta concentração de 
$\mathrm{N}\left(70 \mathrm{mg} \mathrm{kg}^{-1}\right)$ e quantidades expressivas de $\mathrm{P}$ (12 mg $\left.\mathrm{kg}^{-1}\right), \mathrm{K}\left(5,53 \mathrm{mg} \mathrm{kg}^{-1}\right)$, entre outros.

Braga et al. (2002), avaliando substratos e níveis de fertirrigação $((0,1,25 ; 2,5 ; 5,0 ; 10,0$ e $20,0 \mathrm{~mL} \mathrm{~L}-1)$ na produção de mudas de pimentão, observaram que o uso de fertirrigação aumentou-o crescimento da parte aérea e antecipou, em pelo menos três dias, o tempo de obtenção das mudas. A altura da parte aérea das mudas de tomate nas doses de $0 ; 1,5$ e 4,5 $\mathrm{mg} \mathrm{dm}^{-3}$ não foram influenciadas nas avaliações após o transplante, apresentando média de $6,41 \mathrm{~cm}, 8,00 \mathrm{~cm}$ e $7,85 \mathrm{~cm}$, respectivamente (Figura 3). Para as doses de 3,0 e 6,0

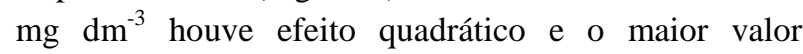
estimado da altura foi 10,95 e 14, 23 aos 50 dias após o transplante, respectivamente.

Andrade (2017) trabalhando com fertirrigação no cultivo de quatro cultivares de tomate (Lycopersicum sculentum) irrigado por gotejamento observou diferença significativa entre as cultivares avaliadas em relação ao valor médio do DC, NFr e PFr quando aplicada a adubação NK via fertirrigação, com exceção para AP. A cultivar Caline IPA 06 (C4) apresentou os melhores resultados para todas as características de crescimento e produção medidas. Observou-se boa correlação entre características medidas (AP, DC, NFr e NFr), ao longo de todo o ciclo desenvolvimento da cultura.

Portanto neste estudo a altura da parte aérea das mudas de tomate nas doses de $0,1,5$ e 4,5 $\mathrm{mg} \mathrm{dm}^{-3}$, não foram influenciadas nas avaliações após o transplante, apresentando média de $6,41 \mathrm{~cm}, 8,00 \mathrm{~cm}$ e $7,85 \mathrm{~cm}$, respectivamente (Figura 3). Para as doses de 3,0 e 6,0 $\mathrm{mg} \mathrm{dm}{ }^{-3}$ houve efeito quadrático e o maior valor estimado da altura foi 10,95 e 14,23 aos 50 dias após o transplante, respectivamente. A Figura 4 mostra em que a dose zero $=5,67$ aos 50 DAS, dose 1,5 $=5,96$ aos 53 DAS, dose 3,0 =6,1 aos 50 DAS, dose 4,5 = 6,29 aos 53 DAS e dose $6,0=7,42$ aos 53 DAS, mas aos 50 DAS teve 3,11 , ambos apresentaram resultados significativos.

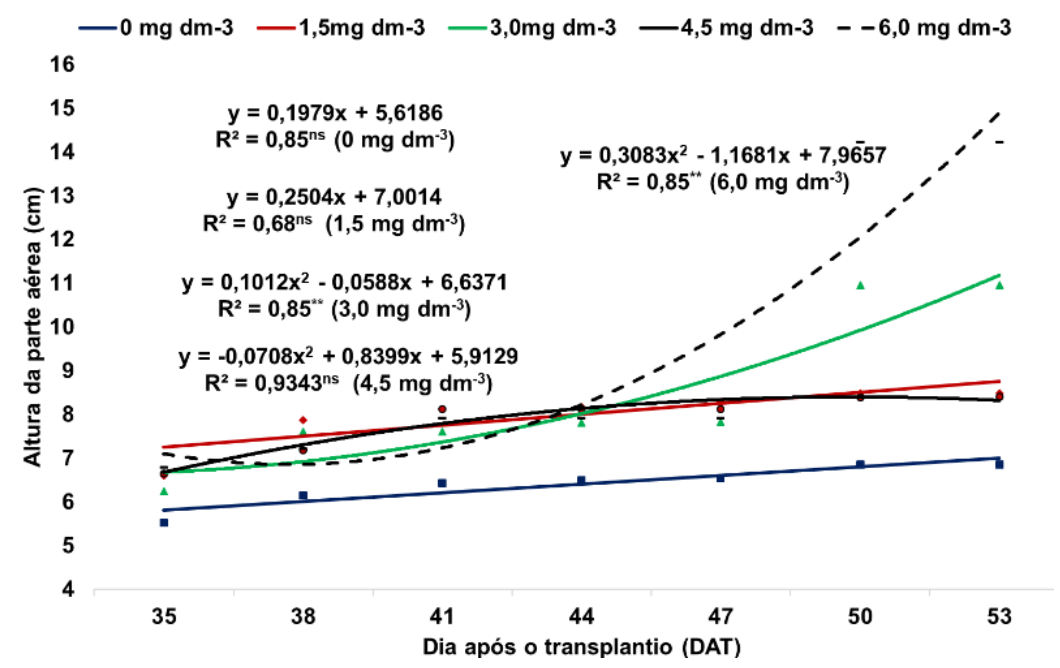

Figura 3. Altura da parte aérea das mudas de tomateiro cv. Marmande no campo, em Nova Xavantina-MT-2016.

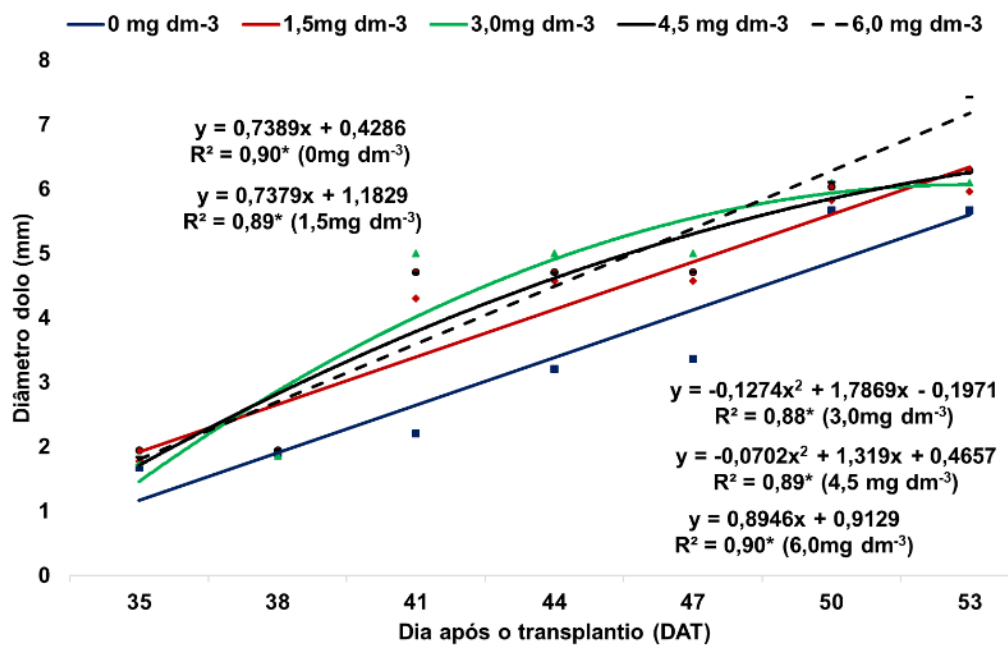

Figura 4. Diâmetro do colo das mudas de tomateiro cv. Marmande no campo, em Nova Xavantina-MT-2016. 
Pires et al. (2009), avaliando o efeito de seis frequências de irrigação no desenvolvimento e na produção do tomateiro cultivado em ambiente protegido observaram que não houve efeito significativo dos tratamentos em relação ao diâmetro da haste nas avaliações de 43 e 99 DAT. Resultado contrário foi obtido por Santana et al. (2010), que estudando níveis de reposição de água no solo, encontraram maior diâmetro de caule no tratamento com $100 \%$ de reposição de água, aos 55, 70, 85 e 100 DAT, onde o excesso de água e o déficit hídrico promoveram menores valores de diâmetro caulinar independente da data de coleta.

As mudas obtiveram maior porcentagem de sobrevivência nas maiores doses $\left(4,5\right.$ e $\left.6,0 \mathrm{mg} \mathrm{dm}^{-3}\right) \mathrm{de}$ NPK. Na figura 05 abaixo mostra a porcentagem de sobrevivência. Filgueira (2003), afirma que um bom enraizamento é o reinício do desenvolvimento da planta, após o choque do processo de transplante são favorecidos por tecidos ricos em massa seca.

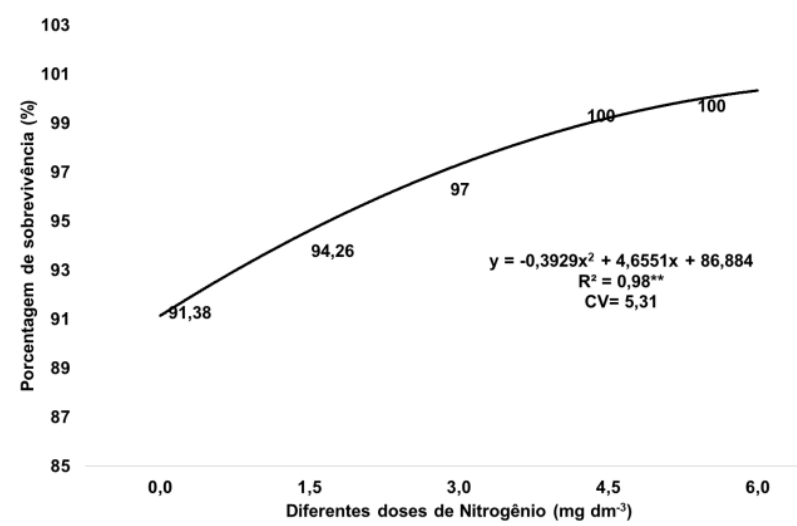

Figura 5. Porcentagem de sobrevivência das mudas de tomateiro cv. Marmande no campo, em Nova Xavantina-MT2016.

\section{Conclusões}

Conclui-se que a cv. Marmande obteve o melhor desenvolvimento, e as mudas quando foram a campo tiveram maior desempenho com doses a partir de 4,5 mg $\mathrm{dm}^{-}{ }^{3}$, mostrando que o tomateiro responde a adubação NPK de forma positiva.

\section{Referências Bibliográficas}

ALVARENGA, M. A. R. Tomate: produção em campo, em casa-de-vegetação e em hidroponia. Lavras-MG: Universidade Federal de Lavras, 2004. 400 p.

BEZERrA, F. C. Produção de Mudas de Hortaliças em Ambiente Protegido. Fortaleza-CE: Embrapa Agroindústria Tropical, 2003. 21 p.

BISCARO, G. A.; TRIGUEIRO, R. de M.; CRUZ, R. L.; LOPES, M. D. C. Germination and development of american lettuce seedlings (Lactuca sativa L.) irrigated with home and industrial effluent-receiving waters. Revista Irriga, BotucatuSP, v. 9, n. 3, pag. 207-216, 2003.

BRAGA, D. O.; SOUZA, R. B.; CARRIJO, O. A.; LIMA, J. L. Produção de mudas de Pimentão em diferentes substratos a base de fibra de coco verde sob fertirrigação Horticultura Brasileira, Brasília-DF, v. 20, n. 4, p. 533-536, 2002.

CAMARGO, P. N. Princípios de nutrição foliar. São PauloSP: Agronômica Ceres Ltda, 1970, 118 p.

CORREIA, D; RIBEIRO, E. M; LOPES, L. S; ROSSETTI, A. G; MARCO, C; A. Uso de pó da casca de coco na formulação de substratos para formação de mudas enxertadas de cajueiro anão-precoce. Revista Brasileira de Fruticultura, Jaboticabal-SP, v. 25, n. 3, p. 557-558, 2003.

ENSINAS, S. C, BISCARO, G. A., BORELLI, A. B.; MÔNACO, K. A.; MARQUES, R. J. R.; ROSA, Y. B. C. J. Níveis de fertirrigação nas características morfofisiológicas de mudas de rúcula. Revista Agrarian, Dourados-MS, v.2, n.3, p.7-17, 2009.

FARIA, C. M. B.; PEREIRA, J. R.; COSTA, N. D.; CORTEZ, C. R.; NAKANE, S.; SILVA, F.A. A, AKVES M. E. Adubação fosfatada em tomateiro industrial em solos do Submédio São Francisco. Horticultura Brasileira, BrasíliaDF, v. 17, n. 2, p. 114-117, 1999.

FERREIRA, D. F. Manual do Sistema Sisvar para análises estatísticas. Lavras-MG: Departamento de Ciências Exatas, Lavras-MG , 2000.

FERREIRA, M. M. M; FERREIRA, G. B.; FONTES, P. C. R. Eficiência da adubação nitrogenada do tomateiro em duas épocas de cultivo. Revista Ceres, Viçosa-MG, v. 57, n. 2, p. 263-273, 2010.

FELTRIN, D. M; POTT, C. A; FURLANI, P. R; LIMONTA, C. C. Produtividade e qualidade de frutos de cultivares de tomateiro Fertirrigado com cloreto e sulfato de potássio. Revista de Ciências Agroveterinárias, Lages-SC, v. 4, n. 1, p. 17-24, 2005.

FILGUEIRA, F. A. R. Novo manual de Olericultura: agrotecnologia moderna na produção e comercialização de hortaliças. Viçosa-MG: Universidade Federal de Viçosa, 3. ed. $2005,412 \mathrm{p}$

FILGUEIRA, J. A. Novo manual de olericultura: agrotecnologia moderna na produção e comercialização de hortaliças. Viçosa-MG: Universidade Federal de Viçosa, 2003. $412 \mathrm{p}$.

IBGE. INSTITUTO BRASILEIRO DE GEOGRAFIA E ESTATÍSTICA. Levantamento sistemático da produção agrícola. Rio de Janeiro-RJ: IBGE, v. 28 n. 12 p. 1-88, 2014.

LARCHER W. Ecofisiologia vegetal. São Carlos-SP: Rima Artes e Textos, 2004. 531 p.

MINAMI, K. Produção de mudas de alta qualidade em horticultura. São Paulo-SP: T.A. Queiroz, 1995. 128 p.

MOREIRA, M. A; DANTAS, F. M; BIANCHINI, F. G; VIÉGAS, P. R. A. Produção de mudas de berinjela com uso de 
pó de coco. Revista Brasileira de Produtos Agroindustriais. Campina Grande-PB, v. 12, n. 2, p. 163-170, 2010.

PEREIRA, P. C.; MELO, B.; FREITAS, R. S.; TOMAZ, M. A.; FREITAS, C. J. P. Mudas de tamarindeiro produzidas em diferentes níveis de matéria orgânica adicionada ao substrato. Revista Verde, Mossoró-RN, v. 5, n. 3, p. 152-159, 2010.

PIRES, R. C. M.; FURLANI, P. R.; SAKAI, E.; LOURENÇÃO, A. L.; SILVA, E. A.; TORRE NETO, A.; MELO, A. M. T. Desenvolvimento e produtividade do tomateiro sob diferentes frequiências de irrigação em estufa. Horticultura Brasileira, Brasília-DF, v. 27, n. 2, p. 228-234, 2009.

SANTANA, M. J.; VIEIRA, T. A.; BARRETO, A. C.; CRUZ, O. C. Resposta do tomateiro irrigado a níveis de reposição de água no solo. Irriga, Botucatu-SP, v. 15, n. 04. p. 443-454, 2010 .
SILVA, J. B. C.; GIORDANO, L. B. Tomate para processamento industrial. Comunicação para transferência de tecnologia. Brasília-DF: Embrapa-CNPH, 2000. 169 p.

SILVEIRA E. B; RODRIGUES V. J. L. B; GOMES A. M. A; MARIANO R. L. R; MESQUITA J. C. P. Pó de coco como substrato para produção de mudas de tomateiro. Horticultura Brasileira, Brasília-DF, v. 20, n. 2, p. 211-216, 2002.

STROMBERGER, J. A.; TSAI, C. Y.; HUBER, D. M. Interactions of potassium with nitrogen and their influence on growth and yield potential in maize. Journal of Plant Nutrition, New York, v. 17, p. 19-37, 1994.

TAIZ, L.; ZEIGER, E. Fisiologia Vegetal. 3. ed. Porto AlegreRS: Artmed, 2004. p. 719. 